\title{
Thoracic psammomatous meningioma with osseous metaplasia: a controversial diagnosis of a case report and literature review
}

\author{
Chao Wang ${ }^{1}$, Yunqing Chen ${ }^{2}$, Lu Zhang ${ }^{3}$, Xuexiao Ma ${ }^{1}$, Bohua Chen ${ }^{1}$ and Shuzhong $\mathrm{Li}^{1^{*}}$
}

\begin{abstract}
Background: Spinal psammomatous meningioma with calcification is commonly observed, but distinctive osseous differentiation rarely occurs.

Case presentation: Here, we described a 52-year-old female complaining of chronic back pain for 5 years. CT and MRI examinations revealed an intradural extramedullary mass at the T4 level. The tumor was meticulously excised en bloc. Under the microscope, the tumor was found to be composed of conspicuous calcified psammoma bodies with remarkable immature bone formation. A primary diagnosis of psammomatous meningioma was made based on the recent WHO classification of tumors of the CNS, whereas other pathologists focused on the osseous components and preferred metaplastic meningioma as the proper subtype. A literature review was conducted, and only five cases have been reported with the same histopathological condition. Experts finally reached a consensus based on the acknowledged notion of the preferential diagnosis of psammomatous meningioma, as well as the current evidence and popular opinion that ossification is generated from osteogenic differentiation of pluripotent cells rather than the accumulation of psammoma bodies.
\end{abstract}

Conclusions: A final diagnosis of psammomatous meningioma with osseous metaplasia was made. The rigid and adherent features complicate total resection of the tumor and increase the risk of neurologic deficits.

Keywords: Meningioma, Psammomatous, Ossification, Thoracic spine, Metaplasia

\section{Background}

Although meningioma is a common benign neoplasm that accounts for $25-46 \%$ of spinal cord tumors, intralesional ossification rarely occurs [1]. When massive intralesional ossification occurs with the presence of conspicuous psammoma bodies, the exact pathological diagnosis is controversial. We searched papers definitely reporting both conspicuous ossification and psammoma bodies, and only five reports were included. For pathological diagnosis, Chotai et al. [9] and Prakash et al. [10] proposed psammomatous meningioma, while Licci et al. [8] and Chang et al. [3] preferred metaplastic meningioma. Therefore, it is

\footnotetext{
*Correspondence: li_shuzhong@163.com

${ }^{1}$ Department of Spinal Surgery, the Affiliated Hospital of Qingdao University,

59, Haier Road, Qingdao 266000, Shandong, China

Full list of author information is available at the end of the article
}

necessary to discuss and clarify the best diagnosis for this special situation. Here, we presented a rare and similar case diagnosed as psammomatous meningioma with osseous metaplasia and elaborated on the reasons for this diagnosis.

\section{Case presentation}

A 52-year-old woman presenting with a 5-year history of chronic back pain was seen at the outpatient center. Previously, the pain had been well controlled with massage and acupuncture, but the pain further deteriorated for 4 months before consulting a doctor and was occasionally induced even with a cough. Furthermore, the patient complained of moderate, intermittent, and painful numbness around the arch of the right rib and the left anterior thigh. She denied weakness and bladder or 
bowel dysfunction. On physical examination, interspinous tenderness was evoked at the T4-5 level without radical pain or paresthesia. Strength in the lower extremities as well as tendon reflexes was normal, and Babinski's sign was negative bilaterally.

Computed tomography showed an intraspinal tumor with high and uneven density on the dorsal side of the canal at the T4 level, with an interspace between the neoplasm and lamina (Fig. 1a, b). Magnetic resonance imaging (MRI) revealed an intradural extramedullary mass that pushed the spinal cord dorsally without obvious compression. The tumor showed hypointensity on both T1 and T2 images compared to the spinal cord (Fig. 1, c-e). According to the image characteristics, the preoperative diagnosis was meningioma.

Surgery was conducted after extensive discussion among the surgeons, and the goal was to remove the tumor safely and completely. A midline back incision was made from $\mathrm{T} 3$ to $\mathrm{T} 5$, and paravertebral muscles were detached subperiosteally and were softly distracted. After a laminectomy of T3 inferiorly, T4 in total, and T5 superiorly with an ultrasonic bone scalpel, the dural sac was exposed without adhesion to the lamina, which was consistent with preoperative imaging. Considering that the dura was rigid and calcified, a longitudinal spindle incision of the dura was made beyond the cephalic and caudal ends of the tumor, after which the tumor was peeled meticulously under spinal cord monitoring.
Although there was little adhesion to the spinal cord, the tumor was tightly adhered to the adjacent arachnoid and dura. Finally, all the tissues were resected, and gross total resection was achieved (Fig. 1f). The patient recovered uneventfully, and she experienced significant improvement in back pain on the day she was discharged. At the 2.5-year follow-up, she experienced only residual numbness on the back, and a subsequent MRI scan showed no evidence of recurrence (Fig. 1g, h).

Grossly, the tumor was a firm entity measuring $1.2 \times$ $1.1 \times 0.9 \mathrm{~cm}$, with adjacent dura and arachnoid (Fig. 1f). After $10 \%$ formalin fixation and decalcification and after being embedded in paraffin and stained with hematoxylin and eosin, the tumor was found to be composed of numerous calcified psammoma bodies under the microscope, with remarkable immature bone formation. Additionally, a rich blood supply was observed in the foci of the bone components, which indicated vigorous bone metabolism (Fig. 2a, b). The meningothelial cells were inconspicuous and lacked mitotic activity and necrosis. Upon immunohistochemical staining, the cells were negative for S100, but positive for epithelial membrane antigen (EMA), somatostatin receptor 2 (SSTR2), and vimentin, which are considered biomarkers of meningioma (Fig. 2c-f).

\section{Discussion and conclusions}

The concept of ossification should be distinguished from calcification in meningioma, although these terms are

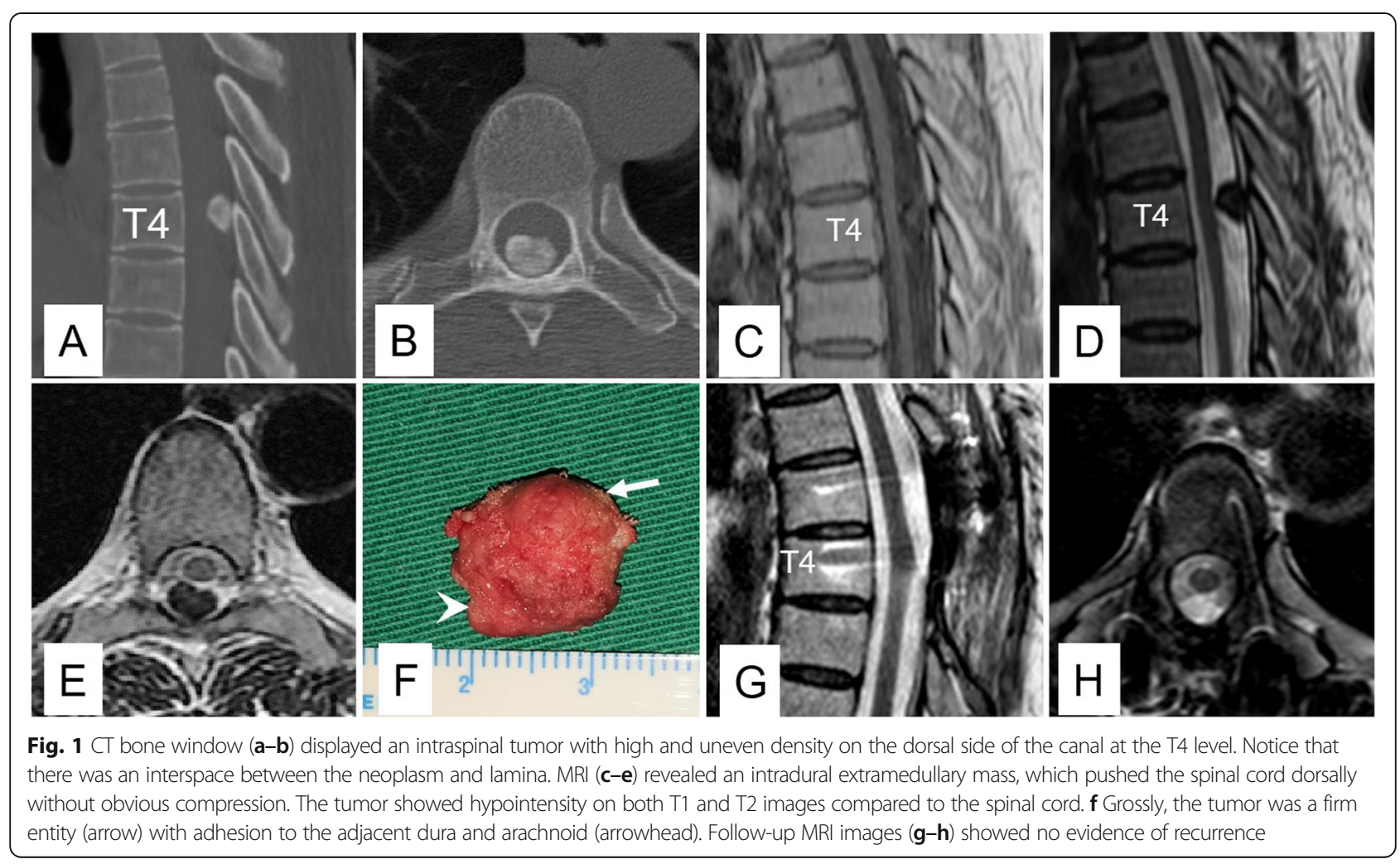




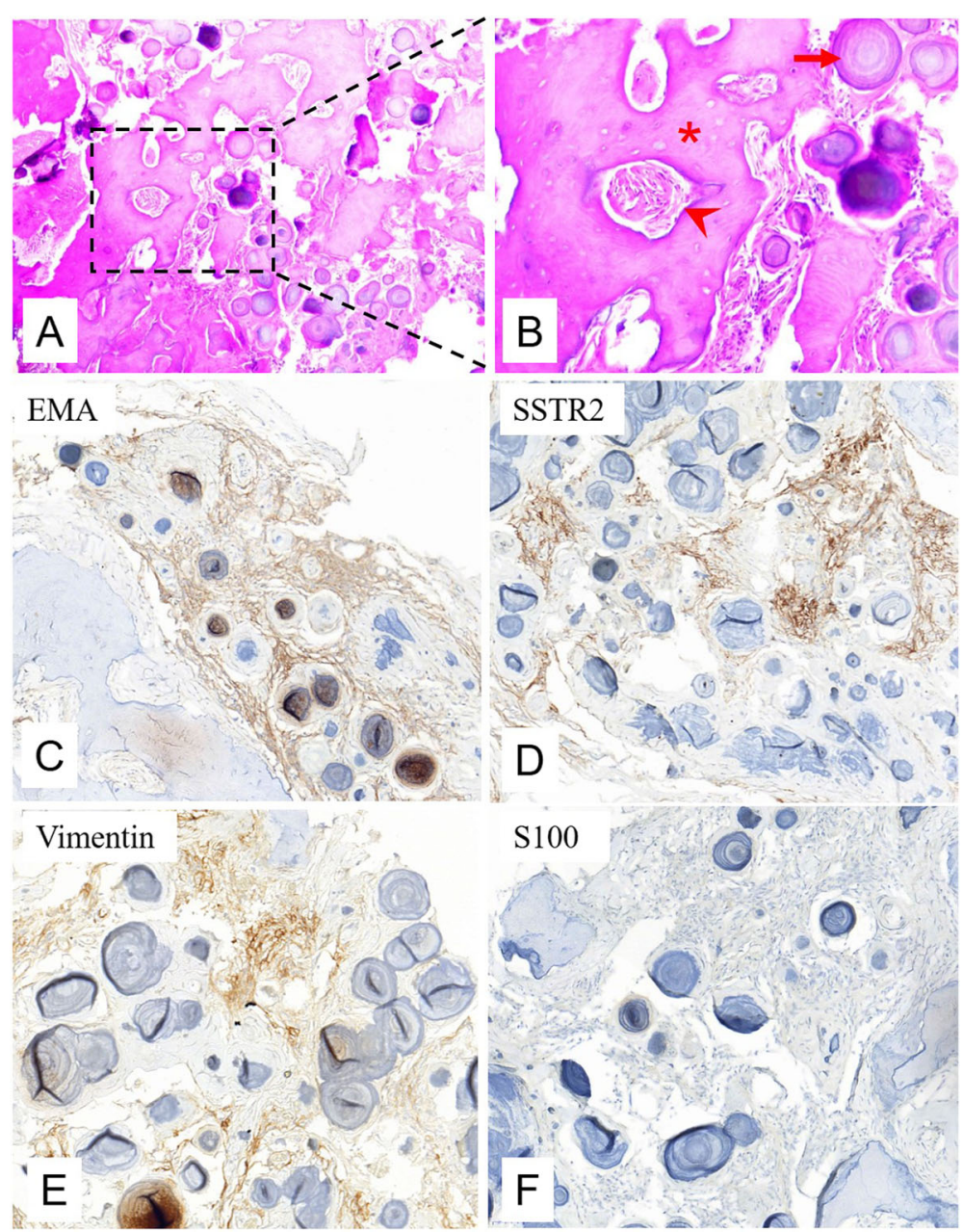

Fig. 2 On H\&E staining $(\mathbf{a} \times 100 ; \mathbf{b} \times 200)$, the lesion was found to be composed of numerous calcified psammoma bodies (arrow), with conspicuous immature trabecular bone formation (asterisk). Additionally, a rich blood supply (arrowhead) was observed in the foci of the bone component. The meningothelial cells were inconspicuous and lacked mitotic activity and necrosis. On immunohistochemical staining (c-f $\mathbf{f} \times 100)$, the cells were positive for epithelial membrane antigen (EMA, c), somatostatin receptor 2 (SSTR2, d), and vimentin (e), but negative for S100 (f)

misused occasionally in the literature [2-4]. Calcification is more of a radiological description than a histopathological diagnosis, and it is usually caused by an accumulation of numerous psammoma bodies and thus is commonly seen in psammomatous meningioma [3]. Ossified meningioma, which manifests as a mature or an immature bone texture within the lesion, is much rarer than calcified meningioma.

When it came to the pathological diagnosis, divergence emerged between the pathologists. The primary diagnosis was psammomatous meningioma based on remarkable psammoma bodies and the following description: "In psammomatous meningioma, the psammoma bodies often become confluent, forming irregular calcified masses and occasionally bone," according to the recent WHO Classification of Tumors of the Central Nervous System [5]. In fact, one hypothesis is that psammoma bodies, which are much more common in spinal meningioma than in intracranial meningioma, can accumulate and assemble as new bone [6]. However, according to the same guidelines, other experts have emphasized the importance of osseous components and have suggested a "metaplastic meningioma" as the revised diagnosis, which is a subtype distinctive from psammomatous meningioma in the WHO classification; by definition, it is "a variant of meningioma with striking focal or widespread mesenchymal components including osseous, cartilaginous, lipomatous, myxoid, and xanthomatous tissue" [5].

To better understand this obscure issue, we searched the PubMed database with the following strategy: ((()(((ossified) OR calcified) OR osteogenic) OR osteoblastic) OR osseous) OR bone) AND spinal) AND meningioma). To eliminate any confusion with the presence of calcification, papers would not be adopted unless 
there was a definite pathological description of ossification. A total of 572 articles were retrieved. After screening the titles and abstracts and excluding irrelevant papers, 19 reports were identified. Finally, we focused on the five cases that involved conspicuous psammoma bodies and ossification (Table 1) [3, 7-10]. Similar to the diagnostic divergence found in our case, the diagnosis was not uniform. Two cases were diagnosed as psammomatous meningiomas, another two were diagnoses as metaplastic meningiomas, and the rest were diagnosed as meningiomas with simultaneous multiple subtypes. After a wide literature review, together with a multidisciplined discussion, we reached a consensus based on the following recognition and evidence.

First, admittedly, both psammomatous meningioma and metaplastic meningioma belong to $\mathrm{WHO}$ grade I, which is prone to a low risk of recurrence after total resection, whether en bloc or piecemeal [5]. Nevertheless, considering the abundance of intralesional psammoma bodies, a preferential designation of "psammomatous meningioma" seems more rational than "metaplastic meningioma," which by definition should contain remarkable mesenchymal components rather than components predominant of other subtypes.

Second, even though the origin of osteogenesis in ossified meningioma remains unclear, most authors prefer to support that it is secondary to metaplasia of meningioma cells into osteoblasts, a process in which pluripotential stem cells could be involved [7, 11, 12]. Uchida et al. [7] speculated that ossification might be induced by exposure to biochemical activity of the ossification cascade or by secretion of osteoblast transforming factors such as Sox9 and Runx2 by mesenchymal premature cells. Metaplastic cells, which represent differentiated premature arachnoid cells, could be immunopositive for bone morphogenetic cytokines and the ossification process in meningiomas. Alafaci et al. [12] found that in 2 of 9 ossified meningiomas, in which no psammoma bodies were identified, foci with immature bone trabeculae and mineralized chondroid matrix were observed, suggesting a pattern of enchondral ossification. Lim et al. [11] successfully isolated what they called meningioma stroma mesenchymal stem-like cells (MS-MSLCs) in meningioma specimens, which could be one component of the meningioma cellular microenvironment, as well as a putative explanation for ossification in meningioma.

Finally, the theory of accumulating psammoma bodies that form bone has vulnerabilities within clinical observations. Although it is true that most ossified cases in the literature were accompanied by psammoma bodies, the ratios of osseous tissues and psammoma bodies are not proportional. In some reports, substantial ossification occurred with sporadic psammoma bodies [2, 13-17]. Moreover, several reports demonstrated obvious ossification but without psammoma body formation [12, 18-21].

Thereafter, the final diagnosis was psammomatous meningioma with osseous metaplasia. Total resection should be the first-line therapy. However, considering the compression and adhesion to the spinal cord due to the hard entity, especially when the tumor is located ventral to the spinal cord, the process of dissection and total resection is sometimes not a viable option. For our patient, as no symptoms or images of spinal cord compression were shown preoperatively, severe adhesion to the spinal cord was not expected. However, the adherent dura and arachnoid were removed for convenience during total resection, and electrophysiological monitoring, including SEP and MEP, was applied for the precaution of spinal cord injury. Other advanced techniques, such as the use of an ultrasonic bone scalpel or aspirator, are recommended for dealing with these thorny masses. Regular follow-ups for postoperative patients are extremely important, especially for those who receive subtotal resections.

In conclusion, we presented a case of subdural meningioma with conspicuous psammoma bodies and osseous metaplasia, and there have only been five similar reports in the literature. The final diagnosis was psammomatous meningioma with osseous metaplasia rather than metaplastic meningioma, which was based on several reasons. The rigid and adherent features complicate the total resection of the tumor and increase the risk of neurologic deficits.

Table 1 Diagnosis of spinal meningiomas with both conspicuous psammoma bodies and ossification

\begin{tabular}{lll}
\hline Year and authors & No. of cases & Summary of diagnosis \\
\hline 2009, Uchida et al. [7] & 1 & Psammomatous, fibrous, and metaplastic meningioma \\
2010, Licci et al. [8] & 1 & Psammomatous, fibrous, and metaplastic meningioma \\
2013, Chotai et al. [9] & 1 & Psammomatous meningioma with osseous metaplasia \\
2014, Chang et al. [3] & 1 & Metaplastic meningioma \\
2017, Prakash et al. [10] & 1 & Psammomatous meningioma with osseous metaplasia \\
Current case & 1 & Psammomatous meningioma with osseous metaplasia \\
\hline
\end{tabular}




\section{Acknowledgements}

None.

\section{Authors' contributions}

CW contributed to the research idea, study design. and data acquisition. YC and LZ analyzed and interpreted the data. XM and BC helped in the statistical analysis. SL helped in the supervision or mentorship. All authors read and approved the final manuscript.

\section{Funding}

None.

\section{Availability of data and materials}

Not applicable.

\section{Ethics approval and consent to participate}

This present study was approved by the Ethics Committee of the Affiliated Hospital of Qingdao University.

\section{Consent for publication}

We have consent for publication from the patient.

\section{Competing interests}

The authors declare that they have no competing interests.

\section{Author details}

${ }^{1}$ Department of Spinal Surgery, the Affiliated Hospital of Qingdao University, 59, Haier Road, Qingdao 266000, Shandong, China. ${ }^{2}$ Department of Pathology, the Affiliated Hospital of Qingdao University, Qingdao, Shandong, China. ${ }^{3}$ Department of Medical Research Center, the Affiliated Hospital of Qingdao University, Qingdao, Shandong, China.

Received: 15 May 2019 Accepted: 16 August 2019

Published online: 24 August 2019

\section{References}

1. Levy WJ Jr, Bay J, Dohn D. Spinal cord meningioma. J Neurosurg. 1982;57(6): 804-12

2. Yamane K, Tanaka M, Sugimoto Y, Ichimura K, Ozaki T. Spinal metaplastic meningioma with osseous differentiation in the ventral thoracic spinal canal. Acta Med Okayama. 2014;68(5):313-6.

3. Chang H, Wu J, Lin D, Chang C, Tu T, Huang W, et al. Calcified meningiomas. J Neurosurg Spine. 2014;20(1):117-8.

4. Zhu Q, Qian M, Xiao J, Wu Z, Wang Y, Zhang J. Myelopathy due to calcified meningiomas of the thoracic spine: minimum 3-year follow-up after surgical treatment. J Neurosurg Spine. 2013;18(5):436-42.

5. Louis DN, Ohgaki H, Wiestler OD, Cavenee WK. WHO classification of tumors of the central nervous system. Lyon: IARC Press; 2016.

6. Kubota T, Sato K, Yamamoto S, Hirano A. Ultrastructural study of the formation of psammoma bodies in fibroblastic meningioma. J Neurosurg. 1984;60(3):512-7.

7. Uchida K, Nakajima H, Yayama T, Sato R, Kobayashi S, Mwaka ES, et al. Immunohistochemical findings of multiple ossified en plaque meningiomas in the thoracic spine. J Clin Neurosci. 2009:16(12):1660-2.

8. Licci S, Limiti MR, Callovini GM, Bolognini A, Gammone V, Di Stefano D. Ossified spinal tumour in a 58-year-old woman with increasing paraparesis. Neuropathology. 2010;30(2):194-6.

9. Chotai SP, Mrak RE, Mutgi SA, Medhkour A. Ossification in an extra-intradural spinal meningioma-pathologic and surgical vistas. Spine J. 2013;13(12):e21-6.

10. Prakash A, Mishra S, Tyagi R, Attri PC, Bhatnagar A, Kansal S. Thoracic psammomatous spinal meningioma with osseous metaplasia: a very rare case report. Asian J Neurosurg. 2017;12(2):270-2.

11. Lim HY, Kim KM, Kim BK, Shim JK, Lee JH, Huh YM, et al. Isolation of mesenchymal stem-like cells in meningioma specimens. Int J Oncol. 2013; 43(4):1260-8

12. Alafaci C, Grasso G, Granata F, Salpietro FM, Tomasello F. Ossified spinal meningiomas: clinical and surgical features. Clin Neurol Neurosurg. 2016; 142:93-7.

13. Freidberg SR. Removal of an ossified ventral thoracic meningioma. Case report J Neurosurg. 1972;37(6):728-30.
14. Niijima K, Huang YP, Malis LI, Sachdev VP. Ossified spinal meningioma en plaque. Spine (Phila Pa 1976). 1993;18(15):2340-3.

15. Naderi S, Yilmaz M, Canda T, Acar U. Ossified thoracic spinal meningioma in childhood: a case report and review of the literature. Clin Neurol Neurosurg. 2001;103(4):247-9.

16. Liu CL, Lai PL, Jung SM, Liao CC. Thoracic ossified meningioma and osteoporotic burst fracture: treatment with combined vertebroplasty and laminectomy without instrumentation: case report. J Neurosurg Spine. 2006; 4(3):256-9.

17. Cochran EJ, Schlauderaff A, Rand SD, Eckardt GW, Kurpad S. Spinal osteoblastic meningioma with hematopoiesis: radiologic-pathologic correlation and review of the literature. Ann Diagn Pathol. 2016;24:30-4.

18. Huang TY, Kochi M, Kuratsu J, Ushio Y. Intraspinal osteogenic meningioma: report of a case. J Formos Med Assoc. 1999;98(3):218-21.

19. Ju Cl, Hida K, Yamauchi T, Houkin K. Totally ossified metaplastic spinal meningioma. J Korean Neurosurg Soc. 2013;54(3):257-60.

20. Mannoji C, Koda M, Murakami M, Kubosawa H, Yamazaki M, Okawa A, et al. Osseous metaplastic meningioma in the thoracic spine mimicking osteosarcoma: a case report. Spine (Phila Pa 1976). 2013;38(10):E632-4.

21. Sakamoto K, Tsutsumi S, Nonaka S, Suzuki T, Ishii H, Ito M, et al. Ossified extradural en-plaque meningioma of the cervical spine. J Clin Neurosci. 2018:50:124-6.

\section{Publisher's Note}

Springer Nature remains neutral with regard to jurisdictional claims in published maps and institutional affiliations.
Ready to submit your research? Choose BMC and benefit from:

- fast, convenient online submission

- thorough peer review by experienced researchers in your field

- rapid publication on acceptance

- support for research data, including large and complex data types

- gold Open Access which fosters wider collaboration and increased citations

- maximum visibility for your research: over $100 \mathrm{M}$ website views per year

At BMC, research is always in progress.

Learn more biomedcentral.com/submissions 